\title{
Variability in Hospital Costs of Adult Spinal Deformity Care
}

Karel Jacobs, MSc, ${ }^{\text {a,b,c,d }}$ Thibault Dewilde, MD, ${ }^{\mathrm{a}, \mathrm{c}}$ Cindy Vandoren, MSc, ${ }^{\mathrm{a}}$ Brecht Cardoen, PhD, ${ }^{\mathrm{d}, \mathrm{e}}$ Nancy Vansteenkiste, MSc, ${ }^{a}$ Lennart Scheys, PhD, ${ }^{\mathrm{a}, \mathrm{c}}$ Filip Roodhooft, PhD, ${ }^{\mathrm{f}, \mathrm{g}}$

Lieven Moke, $\mathrm{PhD},{ }^{\mathrm{a}, \mathrm{c}}$ and Katrien Kesteloot, $\mathrm{PhD}^{\mathrm{a}, \mathrm{b}}$

Study Design. Retrospective, single-center analysis.

Objective. To calculate the total clinical hospital cost of the Adult Spinal Deformity (ASD) care trajectory, to explain cost variability by patient and surgery characteristics, and to identify areas of process improvement opportunities.

Summary of Background Data. ASD is associated with a high financial and clinical burden on society. ASD care thus requires improved insights in costs and its drivers as a critical step toward the improvement of value, i.e., the ratio between delivered health outcome and associated costs.

Methods. Patient characteristics and surgical variables were collected following ethical approval in a cohort of 139 ASD patients, treated between December, 2014 and January, 2018. Clinical hospital costs were calculated, including all care activities, from initial consultation to 1 year after initial surgery (excl. overhead) in a university hospital setting. Multiple linear regression analysis was performed to analyze the impact of patient and surgical characteristics on clinical costs.

Results. $75.5 \%$ of the total clinical hospital cost $(€ 27,865)$ was incurred during initial surgery with costs related to the operating theatre $(80.3 \%)$, nursing units $(11.9 \%)$, and intensive care $(2.9 \%)$

From the ${ }^{a}$ University Hospitals Leuven, Leuven, Belgium; ${ }^{\mathrm{b}} \mathrm{KU}$ Leuven, Faculty of Medicine, LIGB (Leuven Institute for Health Policy), Leuven, Belgium; ${ }^{C} \mathrm{KU}$ Leuven, Faculty of Medicine, Institute for Orthopaedic Research and Training, Leuven, Belgium; 'Vlerick Business School, Technology and Operations Management, Gent, Belgium; ${ }^{e} \mathrm{KU}$ Leuven, Faculty of Economics and Business, Center for Operations Management, Leuven, Belgium; ${ }^{f} \mathrm{KU}$ Leuven, Faculty of Economics and Business, Research Centre Accountancy, Leuven, Belgium; and ${ }^{\mathrm{g}}$ Vlerick Business School, Accounting and Finance, Gent, Belgium

Acknowledgment date: December 2, 2019. First revision date: January 25, 2020. Acceptance date: February 19, 2020.

The manuscript submitted does not contain information about medical device(s)/drug(s).

The KU Leuven grant (C24/17/095) funds were received in support of this work.

Relevant financial activities outside the submitted work: grants, employment.

Address correspondence and reprint requests to Karel Jacobs, MSc, Algemene Directie, University Hospitals Leuven, Herestraat 49, 3000 Leuven, Belgium; E-mail: karel.jacobs@uzleuven.be

DOI: 10.1097/BRS.0000000000003497 being the largest contributors. $57.5 \%$ of the variation in total cost could be explained in order of importance by surgical invasiveness, age, coronary disease, single or multiple-staged surgery, and mobility status. Revision surgery, unplanned surgery due to complications, was found to increase average costs by $87.6 \%$ compared with elective surgeries ( $€ 44,907( \pm € 23,429)$ vs. $€ 23,944$ ( $\pm € 7302)$ ).

Conclusion. This study identified opportunities for process improvement by calculating the total clinical hospital costs. In addition, it identified patient and treatment characteristics that predict $57.5 \%$ of cost variation, which could be taken into account when developing a payment system. Future research should include outcome data to assess variation in value.

Key words: adult spinal deformity, ASD-surgical invasiveness score, cost drivers, costs, value-based healthcare, variation in costs.

Level of Evidence: 4

Spine 2020;45:1221-1228

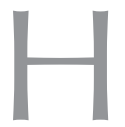

ealthcare providers, working with limited healthcare budgets, attempt to achieve better clinical outcomes at lower costs of care and thus, maximize the value in healthcare. ${ }^{1}$ Particularly in chronic disorders, such as Adult Spinal Deformity (ASD), ${ }^{2}$ characterized by a lifelong outcome and cost impact, value improvements are potentially beneficial, for both society, patients, and care providers.

Accurate cost data are essential in the search for process improvement. ${ }^{3}$ Similar to other diseases, ${ }^{3}$ "costs" in ASD literature are based on reimbursement data $^{4-7}$ and/or the scope is limited to the index surgery. ${ }^{4,5,8}$ Instead, costs ideally reflect the monetary value of the largest possible part of all resources used during the entire patient's care trajectory, ${ }^{9}$ rather than the peculiarities of different reimbursement systems.

Furthermore, in many countries, innovative reimbursement systems are developed in an attempt to control increasing healthcare costs. Bundled payments ${ }^{10,11}$ are one such attempt. Hereby, a fixed amount is reimbursed for all providers in the care trajectory for a certain patient group, 
during a certain period of time. It aims to promote clinical continuity and to align incentives for care providers around value instead of volume. ${ }^{12}$ An important challenge in introducing bundled payments is the differences in "justified care" 13 for different subgroups. There is, for instance, risk of patient cherry-picking (e.g., patients without comorbidities or favorable surgical episodes) when the bundled payment would not take these factors into account. Data on true costs, including its variability drivers, are needed to implement a bundled payment system that encourages to provide the right care, without inducing adverse selection.

Accordingly, this paper aims to identify the drivers of the total clinical hospital costs of the ASD care trajectory in an academic referral center. We hypothesize 1) that we can explain cost variability by patient and surgical characteristics, needed to move from fee for service to bundled payments and 2) that we will be able to identify areas of process improvement opportunities in the care pathway.

\section{MATERIALS AND METHODS}

This study was approved by the KULeuven ethical committee (S61657) and took place at University Hospitals Leuven. One hundred thirty-nine ASD patients met the inclusion criteria and were enrolled in the current study. Patients with lumbar spondylolisthesis, adolescent idiopathic scoliosis, Scheuermann kyphosis, neuromuscular (kyfo-)scoliosis, de novo degenerative scoliosis, and (iatrogenic) flat back deformity were included. Initial (=index) surgery was performed between December 2014 and January 2018. The study population was divided into two subgroups, depending on the number and nature of surgical episodes during the 1-year follow-up period. The first subgroup entailed all patients with one $(n=92)$ or several $(n=22)$ planned surgeries (Gr1_planned). The second subgroup entailed patients with at least one revision surgery due to complications $(\mathrm{n}=25)$ (Gr2_revision). Both clinical and cost data were collected for all patients.

\section{Clinical Data}

Clinical data were collected retrospectively between August and December 2018 via electronic patient record analyses on demographics, comorbidities, and surgical characteristics (see Table 1). Next to the American Society of Anesthesiologists -score, the five-item modified frailty index (5i$\mathrm{mFI})^{14}$ was calculated to score the patient's physiological status based on the presence of diabetes mellitus, congestive heart failure, hypertension requiring medication, history of COPD, and a partially dependent functional status. The 5i-mFI has been demonstrated to correlate with the length of stay (LOS), readmission, and complications ${ }^{14}$ and could thus affect costs. In addition, the ASD surgical invasiveness score ${ }^{15}$ (ASD-S) was calculated. ${ }^{15}$ Vertebral column resection was scored in the same way as a three-column osteotomy. For every patient, a second ASD-S score was determined, adding up all ASD-S scores of the individual

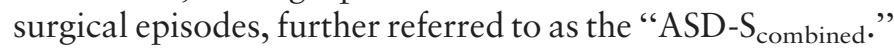

Finally, patients' primary diagnoses were labeled using The Spine Tango ${ }^{16}$ diagnostic classification.

\section{Cost Data}

The clinical cost of the care trajectory analyzed in our study equals the sum of the different costs of all in- and outpatient pre-, peri-, and postoperative services, provided within the university hospital. Both direct and indirect costs of clinical care within the hospital are included.

Medication and implants were registered per patient and are therefore direct costs, directly attributed to the patients. Other clinical hospital costs were allocated on the basis of the classic two-stage ABC-allocation principle, ${ }^{17}$ using the data of the hospital's own Activity Centre-Care program ${ }^{18}$ model. This model permits calculating the costs of the care trajectory within the hospital by taking the different activities and their frequency per patient into account. First, costs of each resource (e.g., nurses, utilities, equipment) are allocated by a resource cost driver to activity centers, which are functional units where each of the activities is performed, such as the operating room, the lab, the ward, etc. Next, the activity cost pool at the level of the activity centers is allocated to patient groups through activity cost drivers, such as the number of X-rays, the operating time, the length of stay.

Costs of supporting services such as administration, cleaning services, or the human resources department are not included in the present analysis because of the limited effect of ASD patients on the total overhead costs. This approach implies that the cost data are mainly suitable to identify and assess cost differences between patient groups or different care approaches-and cannot be used to set "full" reimbursement rates (although the data could be used to differentiate reimbursement rates between subgroups of patients).

This total clinical cost of the hospital care trajectory will be further referred to as the total cost per patient, although it should be kept in mind that this "total" cost does not include overhead costs.

\section{Statistics}

Statistical analyses were carried out using SPSS software (v. 25.0.0; SPSS Inc, Chicago, IL). Descriptive statistics including means and standard deviations were performed on patient and surgery characteristics, as well as on costs. Independent $t$ tests were performed to assess the differences in patient and treatment characteristics between GR1_planned and GR2_revision. In addition, bivariate linear correlation analyses were used to assess the level of correlation between patient and treatment characteristics on the one hand and the total cost per patient on the other hand. Means and variation of the total cost per patient were calculated and compared between subgroups. The nonparametric Mann-Whitney $U$ and Kruskall-Wallis test, combined with posthoc tests if needed, were performed, to examine the link between the independent categorical variables and the dependent right-skewed variable of the total 


\begin{tabular}{|c|c|c|c|c|c|}
\hline Characteristic & $\begin{array}{l}\text { All Included } \\
\text { Patients } \\
(n=139)\end{array}$ & \begin{tabular}{c|}
$P$ (Sign. \\
Correlation \\
With Total Cost)
\end{tabular} & $\begin{array}{l}\text { Statistic } \\
\text { Gr1_planned } \\
(\mathbf{n}=114)\end{array}$ & $\begin{array}{l}\text { Gr2- } \\
\text { revision } \\
(n=25)\end{array}$ & $\begin{array}{c}P \text { (Sign. Differ- } \\
\text { ence Between } \\
\text { Subgroups) }\end{array}$ \\
\hline \multicolumn{6}{|l|}{ Demographics } \\
\hline Mean age in years (SD) & $55.4( \pm 17.2)$ & $0.015^{\S}$ & $54.0( \pm 17.5)$ & $61.4( \pm 14.4)$ & $0.046^{\S}$ \\
\hline Female $(\%)$ & $94(67.6 \%)$ & 0.675 & $78(69.0 \%)$ & $16(61.5 \%)$ & 0.462 \\
\hline Mean body mass index (SD) & $25.6( \pm 4.7)$ & 0.050 & $25.2( \pm 4.4)$ & $27.3( \pm 5.5)$ & $0.045^{\S}$ \\
\hline Mobility status & & $0.024^{\S}$ & & & 0.301 \\
\hline Walking independently (\%) & $109(78.4 \%)$ & $0.012^{\S}$ & $91(80.5 \%)$ & $18(69.2 \%)$ & \\
\hline Walking with device (\%) & $25(18.0 \%)$ & 0.075 & $18(15.9 \%)$ & $7(26.9 \%)$ & \\
\hline Wheelchair bound (\%) & $5(3.6 \%)$ & 0.057 & $4(3.5 \%)$ & $1(3.9 \%)$ & \\
\hline Functional status & & $0.003^{\S}$ & & & 0.314 \\
\hline Living independently & $110(79.1 \%)$ & $0.001^{\S}$ & $92(81.4 \%)$ & $18(69.2 \%)$ & \\
\hline Living partially dependently & $23(16.5 \%)$ & $0.010^{\S}$ & $16(14.2 \%)$ & $7(26.9 \%)$ & \\
\hline Living dependently & $6(4.3 \%)$ & 0.054 & $5(4.4 \%)$ & $1(3.8 \%)$ & \\
\hline Smoking (\%) & $34(24.5 \%)$ & 0.360 & $27(23.9 \%)$ & $7(26.9 \%)$ & 0.746 \\
\hline \multicolumn{6}{|l|}{ Primary diagnosis } \\
\hline Degenerative deformity & $91(65.5 \%)$ & $0.000^{\S}$ & $70(62.0 \%)$ & $21(80.8 \%)$ & 0.076 \\
\hline Nondegenerative deformity & $26(18.7 \%)$ & 0.130 & $25(22.1 \%)$ & $1(3.9 \%)$ & 0.061 \\
\hline Foraminal stenosis & $7(5.0 \%)$ & 0.885 & $6(5.3 \%)$ & $1(3.9 \%)$ & 0.759 \\
\hline Central stenosis & $6(4.3 \%)$ & $0.014^{\S}$ & $5(4.4 \%)$ & $1(3.9 \%)$ & 0.896 \\
\hline Others & $9(6.5 \%)$ & $0.002^{\S}$ & $7(6.2 \%)$ & $2(7.7 \%)$ & 0.780 \\
\hline \multicolumn{6}{|l|}{ Comorbidities $^{*}$} \\
\hline Arterial hypertension & $36(25.9 \%)$ & 0.711 & $27(23.9 \%)$ & $9(34.6 \%)$ & 0.264 \\
\hline Mitral valve prolapse & $22(15.8 \%)$ & 0.350 & $19(16.8 \%)$ & $3(11.5 \%)$ & 0.509 \\
\hline Osteoporosis & $20(14.4 \%)$ & 0.976 & $17(15.0 \%)$ & $3(11.5 \%)$ & 0.647 \\
\hline Spinal cord injury & $17(12.2 \%)$ & 0.219 & $12(10.6 \%)$ & $5(19.2 \%)$ & 0.234 \\
\hline Depression & $10(7.2 \%)$ & 0.839 & $7(6.2 \%)$ & $3(11.5 \%)$ & 0.349 \\
\hline Modified Frailty index ${ }^{\dagger}$ & & $0.039^{\S}$ & & & $0.039^{\S}$ \\
\hline Nonfrail & $76(54.7 \%)$ & & $66(58.4 \%)$ & $10(38.5 \%)$ & \\
\hline Frail & $45(32.4 \%)$ & & $35(31.0 \%)$ & $10(3.5 \%)$ & 0.096 \\
\hline Severely frail & $18(13.0 \%)$ & & $12(10.6 \%)$ & $6(23.1 \%)$ & \\
\hline \multicolumn{6}{|l|}{ Surgery characteristics } \\
\hline ASD-S score $(\mathrm{SD})$ & $32.7( \pm 12.5)$ & $<0.001^{\S}$ & $33.5( \pm 13.0)$ & $29.3( \pm 10.0)$ & 0.128 \\
\hline ASD-S combined $_{\text {(SD) }}$ & $37.2( \pm 15.7)$ & $<0.001^{\S}$ & $36.0( \pm 15.2)$ & $42.6( \pm 16.6)$ & 0.061 \\
\hline LOS initial hospitalization (SD) & $11.8( \pm 9.1)$ & $<0.001^{\S}$ & $10.4( \pm 4.1)$ & $18.0( \pm 18.4)$ & $0.02^{\S}$ \\
\hline Combined LOS care trajectory $y^{\ddagger}$ (SD) & $19.0( \pm 23.1)$ & $<0.001^{\S}$ & $13.4( \pm 10.8)$ & $43.1( \pm 41.1)$ & $<0.01^{\S}$ \\
\hline \\
\hline \multicolumn{6}{|c|}{$\begin{array}{l}\text { Numbers are rounded to the first decimal place. } \\
\text { "Comorbidities with less than five observations such as Parkinson, cerebral palsy, congestive heart failure, etc., were not visualized and excluded from further statistics. } \\
\text { 'Modified frailty index: frailty was scored on five items including diabetes mellitus, congestive heart failure, hypertension requiring medication, history of } \\
\text { COPD, and functional status: partially dependent. The authors categorized patients with } 0,1 \text {, and } 2 \text { or more on a scale of } 5 \text { as resp. "non-frail," "frail," and } \\
\text { "severely frail," respectively. }\end{array}$} \\
\hline
\end{tabular}

cost per patient. Finally, a multiple linear regression model was used to explain the total cost per patient, the costs of the three phases (preparation, initial intervention, and follow-up phase), and the cost of initial surgery. Logarithmic (natural base) transformations were performed for follow-up costs and total cost per patient to deal with their skewed distribution. For all analyses, the level of significance was set at 0.05 and assumptions were validated.

\section{RESULTS}

\section{Patient and Surgery Characteristics}

One hundred thirty-nine ASD patients were included in this study. $67.6 \%$ were female and $24.5 \%$ were smoking. The BMI ranged from $16.1 \mathrm{~kg} / \mathrm{m}^{2}$ to $40.1 \mathrm{~kg} / \mathrm{m}^{2}$ with $25.6 \mathrm{~kg} / \mathrm{m}^{2}$ as average. $18.0 \%$ of patients were walking with a device, $3.6 \%$ were wheelchair-bound, whereas $78.4 \%$ could walk independently. $16.5 \%$ were living partially dependent (with 


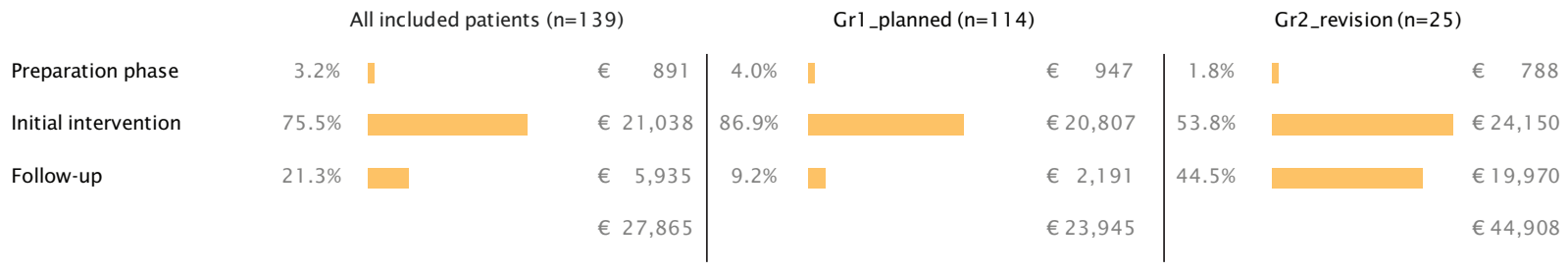

Figure 1. The relative contribution of the different phases to the total cost per patient for all patients, Gr1_planned and Gr2_revision.

the help from a nurse or a relative), $4.3 \%$ were living completely dependent (e.g., in a retirement home), 79.1\% lived independently. $96.4 \%$ of all patients had at least one comorbidity. Most common comorbidities were arterial hypertension $(25.9 \%)$, mitral valve prolapse $(15.8 \%)$, osteoporosis $(14.4 \%)$, spinal cord injury $(12.2 \%)$, and depression $(7.2 \%)$. The most common primary diagnoses were degenerative deformity $(65.5 \%)$ and nondegenerative deformity $(18.7 \%)$, followed by foraminal stenosis $(5.0 \%)$ and central stenosis $(4.3 \%)$. Independent $t$ tests revealed significant differences between Gr1_planned and Gr2_revision in age, BMI, and modified frailty-index.

The ASD-S of the initial surgical episode was 32.7 (range 7-77). The mean ASD-S combined $_{\text {wa }} 37.2$ (range 7-144). The average LOS of the initial surgical episode was $11.8 \pm 9.1$ days and the average combined LOS of all hospital stays during the defined care trajectory was $18.9 \pm 23.1$ days. Independent $t$ tests revealed significant differences between Gr1_planned and Gr2_revision in LOS of the initial hospitalization and the combined LOS. Table 1 gives a detailed overview of all patient and surgery characteristics, both overall and on subgroup level.

\section{Costs}

The average total cost per patient of the entire 1-year care trajectory was $€ 27,865(\mathrm{n}=139)$ with a standard deviation of $€ 14,493$. On average, the largest part of these costs is incurred during the initial intervention and hospital stay $(75.5 \%) .21 .3 \%$ of costs were incurred during the follow-up phase, $3.2 \%$ was incurred during the preparation phase (Figure 1). During the initial intervention and hospital stay, the bulk of costs was incurred in the operating theater $(80.3 \%)$ with the most important cost categories being implants $(32.9 \%)$, other materials $(16.1 \%)$, medical and nonmedical staff (resp. 13.9\% and $12.1 \%$ ). A breakdown of initial intervention costs is found in Figure 2.

As summarized in Table 1, age, BMI, mobility status, functional status, degenerative deformity, central stenosis, other diagnosis, modified frailty index, ASD-S, ASD-S combined, $_{\text {, }}$ and length of stay, were all significantly related to the total cost per patient.

As shown in Figure 3, revision surgery (Gr2_revision) was found to increase costs by $87.6 \%$ compared with elective surgery (Gr1_planned), with average costs of resp. $€ 44,907$ and $€ 23,944$. This increase was additionally associated with an increased standard deviation of resp. $\pm €$

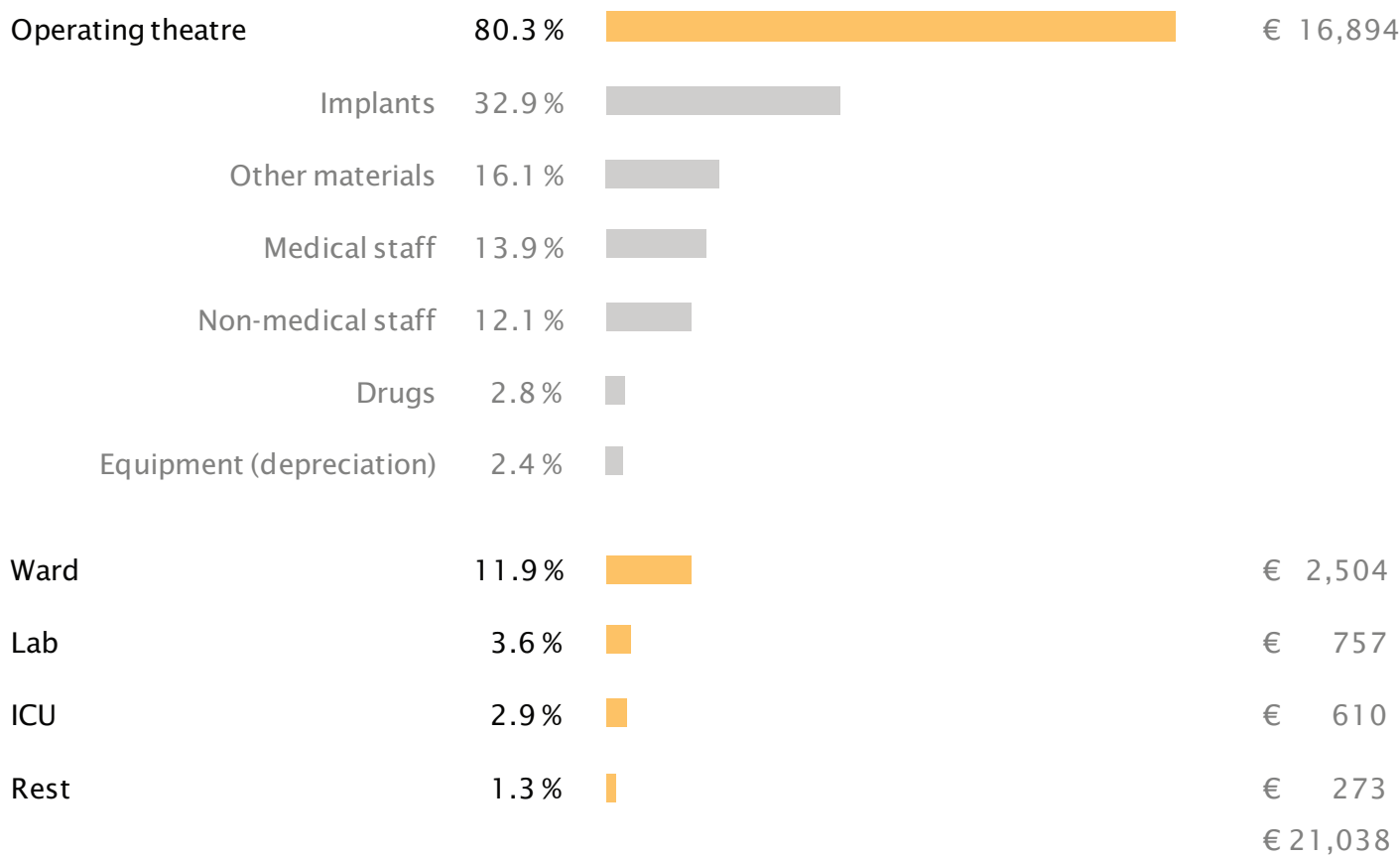

Figure 2. Relative contribution to the cost of the initial intervention and hospital stay. 


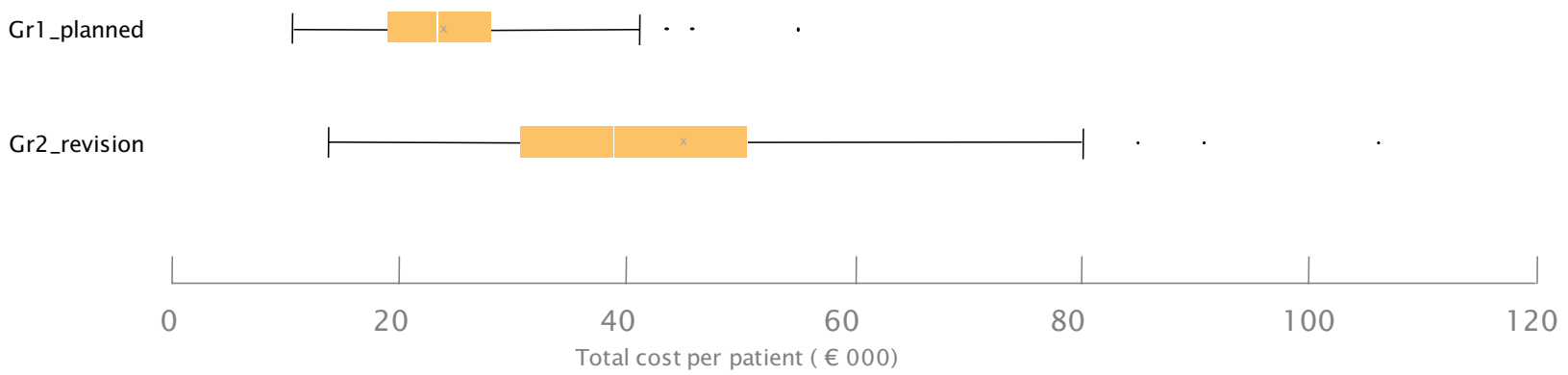

Figure 3. Boxplot comparing total clinical hospital costs (€ $1000 \mathrm{~s})$ between Gr1_planned and Gr2_revision. The white line within each box represents the mean, the $X$ represents the average. The whiskers extend to the most extreme data point within the range of $1.5 \times I Q R$ from the box. Outliers, data points outside the range of the whiskers are shown as dots.

23,429, compared with $\pm € 7302$. The follow-up phase showed the largest significant difference $(P$ value $<0.001)$ in costs between Gr2_revision (€19,969) and Gr1_planned (€ 2191).

Figure 4 shows the average cost per phase with standard deviation for all patients and for the subgroups separately. The quartile coefficient of dispersion shows that the initial intervention, overall and for each subgroup, has the least relative variation. In contrast, the cost of the follow-up phase is characterized by a large variation.

Table 2 summarizes the different stepwise linear regression models, including regression coefficients, $P$ values, and $\mathrm{R}^{2}$. Variation in total cost per patient could be explained, in order of importance, by the ASD-S $\mathrm{S}_{\text {combined, }}$ age, coronary disease, multiple versus single planned surgery, and mobility status. Together, these variables explain $57.5 \%$ of variation. $43.0 \%$ of the variation in initial surgery cost could be explained by the ASD-S and American Society of Anesthesiologists score only.

\section{DISCUSSION}

The purpose of this study was to calculate the total cost per patient of the ASD (1-year) care trajectory and examine its variability at an academic referral center, to identify the cost of the different phases of the hospital care trajectory and to investigate causes of cost variations between subgroups of patients.

Overall, the initial surgery accounted for $75.5 \%$ of the total clinical hospital cost, which is in line with recent literature. ${ }^{19}$ A large proportion $(80.3 \%)$ of these costs was incurred in the operating theater, which makes the surgery the primary focus for value improvement for this population. As such, ASD-S is a good candidate to support more precise planning of surgery time slots and adjust the standard average times that are currently in place at our hospital. Indeed, this study showed that the ASD-S predicts almost half of the variation in surgery time. $88.5 \%$ of index surgeries had at least 30 minutes overtime, with $64.7 \%$ of surgeries exceeding 2 hours of overtime, resulting in 410 hours of total overtime. In addition, $4.3 \%$ of surgeries were at least 30 minutes shorter than originally planned. ASD-S-based surgery time allocation is thus expected to be more in line with reality and thus allow better use of excess capacity or avoiding over time resulting in a lower capacity cost rate.

Thirdly, surgeons and management could use these data to decide on investments in techniques or changes in the work flow, which reduce surgery time. Because our model includes all activities over the care cycle period, it will be possible to check how such changes in work flow, or new techniques are beneficial over the entire care trajectory (e.g., can the introduction of a team briefing pre and postsurgery (thereby increasing staff time) reduce the operating time (thereby reducing-more expensive-OT staff time?)).

At University Hospitals Leuven, surgeons currently plan preoperative examinations according to the presented comorbidities of the patient. Therefore, it was expected that variability in the costs of the preoperative phase could be predicted, based on the presented comorbidities. However, this was not reflected in our data. More in-depth analyses showed that the preoperative preparation was not as standardized as presumed. Therefore, our data suggest an opportunity for adopting a more standardized evidence-based workflow of preoperative examinations and corresponding actions depending on the comorbidities of the patient, following the guidelines ${ }^{20}$ of the Belgian Health Care Knowledge Centre.

Evidently, we strive to avoid revision surgery due to complications, both for quality and cost reasons. Indeed, this study illustrates that revision surgery due to complications (infection, material failure, and neuro-compression) significantly increases costs (total cost per patient of $€$ 44,907 instead of $€ 23,429$ ). These insights can help to decide on investment strategies. Theoretically, investing in a technique that costs $€ 2262$ per patient, bringing down revision surgery due to complications by $50 \%$ from $22.0 \%$ to $11.0 \%$ would be breakeven (i.e., no extra cost) and thus, be justifiable, from an economic point of view (due to better outcomes, i.e., less complications).

The second aim of this study was to identify drivers of the variability in the total clinical hospital costs. As a recent study concluded, ${ }^{11}$ accounting for payment variation would be the greatest challenge in spine surgery when moving to bundled payments. ASD-S $S_{\text {combined, }}$ age, coronary disease, one or multiple planned surgeries, and mobility status were all found to affect the total cost per patient. Therefore, these 


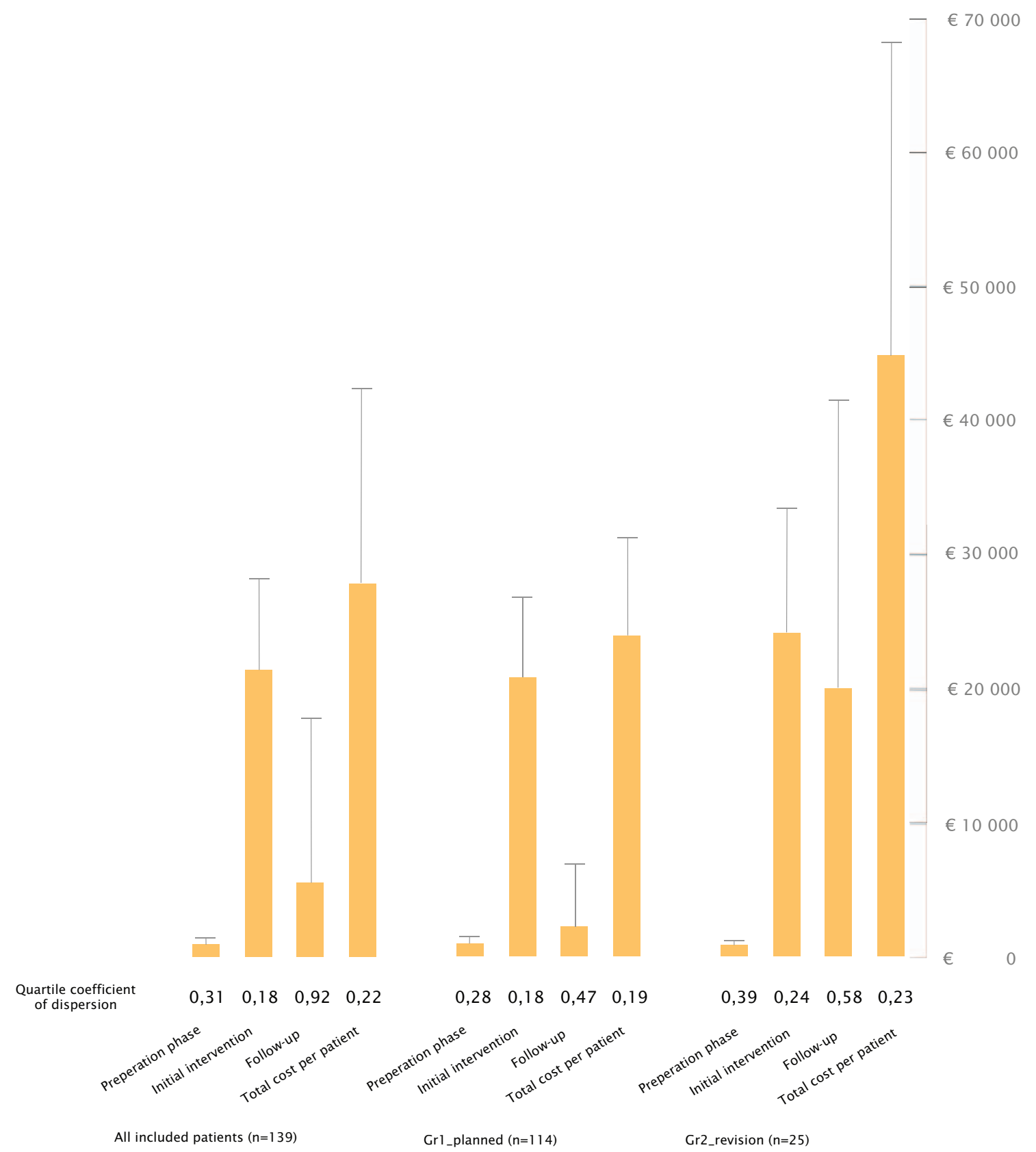

Figure 4. Error Bar chart representing the average cost per phase with SD (whiskers) for all patients and for Gr1_planned and Gr2_revision separately.

factors should be included in a risk-adjusted bundled payment system, as seen in other payment models in spine surgery. ${ }^{12,21}$

The results of this study must be interpreted within the context of its design. First, the clinical data were gathered retrospectively and are susceptible to registration bias. If a certain comorbidity was not documented in the patient record due to incomplete registration, it was incorrectly assumed that this patient did not have that comorbidity. Second, cost analyses were performed only at a tertiary academic center. Costs of care provided outside the hospital, for example, GP consultations, home medication, or ambulatory physiotherapy services were not included because of a lack of data on these activities within the current study design. Third, only care-related hospitals costs were taken into account. Overhead hospital costs were excluded because adding these costs would not add additional insights into true reasons for variation in the cost data. Furthermore, these costs are not expected to be affected when improving care delivery.

In conclusion, this study identified the total cost of care over the full 1-year hospital cycle and its composition, together with areas of process improvement opportunities. It also identified variability drivers to the total cost of care, needed for bundled payments. Further research should focus on including costs incurred outside the hospital and on 


\begin{tabular}{|c|c|c|c|}
\hline Total Clinical Hospital Cost* & Coefficient $(\beta)$ & $P$ Value & $\mathbf{R}^{2}$ \\
\hline Intercept & 4921 & $<0.001$ & 0.575 \\
\hline Surgical invasiveness score combined & $0.014 p$ & $<0.001$ & \\
\hline Age & 0.004 & 0.002 & \\
\hline Coronary disease & 0.500 & 0.001 & \\
\hline Multiple planned surgeries & 0.209 & 0.001 & \\
\hline \multicolumn{4}{|l|}{ Mobility status } \\
\hline Walking with device & 0.141 & 0.023 & \\
\hline Wheelchair-bound & 0.259 & 0.045 & \\
\hline Cost preparation phase ${ }^{\dagger}$ & Coefficient $(\beta$, euros) & $P$ value & $\mathbf{R}^{2}$ \\
\hline Intercept & 891 & $<0.001$ & 0.055 \\
\hline \multicolumn{4}{|l|}{ Functional status } \\
\hline Living dependently & 589 & 0.005 & \\
\hline Cost initial hospitalisation $^{\dagger}$ & Coefficient ( $\beta$, euros) & $P$ value & $\mathbf{R}^{2}$ \\
\hline Intercept & 10,286 & $<0.001$ & 0.474 \\
\hline Surgical invasiveness score & 295 & $<0.001$ & \\
\hline \multicolumn{4}{|l|}{ Mobility status } \\
\hline Walking with device & 4004 & 0.001 & \\
\hline Wheelchair-bound & 14,037 & $<0.001$ & \\
\hline Carotid artery disease & 6419 & 0.002 & \\
\hline Cerebral palsy & $-10,423$ & 0.003 & \\
\hline Previous blood clot ${ }^{\ddagger}$ & 4621 & 0.049 & \\
\hline Cost follow-up* & Coefficient $(\beta)$ & $P$ value & $\mathbf{R}^{2}$ \\
\hline Intercept & 4024 & $<0.001$ & 0.335 \\
\hline Surgical invasiveness score combined & $0.040 \mathrm{n}$ & $<0.0011$ & \\
\hline Coronary disease & 2.240 & 0.004 & \\
\hline Age & 0.020 & 0.006 & \\
\hline Diabetes mellitus & 1.181 & 0.014 & \\
\hline Other neurological disorders & 0.676 & 0.017 & \\
\hline Cost initial surgery ${ }^{\dagger}$ (operating theater) & Coefficient $(\beta$, euros) & $P$ value & $\mathbf{R}^{2}$ \\
\hline Intercept & 8897 & $<0.001$ & 0.430 \\
\hline Surgical invasiveness score & 240 & $<0.001$ & \\
\hline ASA score of 3 & 1445 & $<0.029$ & \\
\hline \multicolumn{4}{|c|}{$\begin{array}{l}\text { "We used a logarithmic transformation for dependent variables with a skewed distribution: } \log Y_{i}=\alpha+\beta X_{i}+\varepsilon_{i} \text { : Each 1-unit increase in } X \text { multiplies the expected } \\
\text { value of } Y \text { by } e^{\beta} \text {. }\end{array}$} \\
\hline \multicolumn{4}{|c|}{$\begin{array}{l}\text { 'We used a general linear model for dependent variables that were normally distributed: } Y_{i}=\alpha+\beta X_{i}+\varepsilon_{i} \text { : Each 1-unit increase in } X \text { increases the expected } \\
\text { value of } Y \text { by } \beta \text {. }\end{array}$} \\
\hline
\end{tabular}

outcome data, to assess changes in value and to move toward outcome-based bundled payments. This cost study was a first step in the shift from outcome to value-driven healthcare for the ASD population.

\section{Key Points}

- The total clinical hospital cost of the 1-year intrahospital ASD surgical care trajectory is $€$ 27,865 ( $\pm €_{14,493)}$ per patient.
Patient characteristics, such as age, coronary disease, and preoperative mobility status, together with surgery characteristics such as the surgical invasiveness index and single versus multiple staged surgery are significant cost predictors in the 1-year intrahospital ASD surgical care pathway.

口 Revision surgery due to complications is a major driver of the total clinical hospital cost, increasing costs by $87.6 \%$ compared with elective surgery. 


\section{Acknowledgments}

The authors thank Kristel Van de Loock for her assistance in writing the protocol, Lore Hermans for her assistance in the statistical analysis, and Maïté Jaspers, Nicolas Himpe, and Anton Boeckxstaens for their assistance in collecting the clinical data.

\section{References}

1. Porter ME. What is value in health care? N Engl J Med 2010; 363:2477-81.

2. Pellisé F, Vila-Casademunt A, Ferrer M, et al. Impact on health related quality of life of adult spinal deformity (ASD) compared with other chronic conditions. Eur Spine J 2014;24:3-11.

3. Kaplan RS, Porter ME. How to solve the cost crisis in Health care. Harv Bus Rev 2011;89:46-52.

4. Kamerlink JR, Quirno M, Auerbach JD, et al. Hospital cost analysis of adolescent idiopathic scoliosis correction surgery in 125 consecutive cases. J Bone Joint Surg Am 2010;92:1097-104.

5. Sapountzi-krepia D, Psychogiou M, Peterson D, et al. Cost minimization in treatment of adult degenerative scoliosis. $X X X$ 2006;7:1-7.

6. Tosteson ANA, Skinner JS, Tosteson TD, et al. The cost effectiveness of surgical versus nonoperative treatment for lumbar disc herniation over two years: evidence from the Spine Patient Outcomes Research Trial (SPORT). Spine (Phila Pa 1976) 2008;33:2108-15.

7. Tosteson AN, Lurie JD, Tosteson TD, et al. Surgical treatment of spinal stenosis with and without degenerative spondylolisthesis: cost-effectiveness after 2 years. Ann Intern Med 2008;149:845-53.

8. McCarthy IM, Hostin RA, O'Brien MF, et al. Analysis of the direct cost of surgery for four diagnostic categories of adult spinal deformity. Spine J 2013;13:1843-8.

9. Porter ME, Kaplan RS. How to pay for health care. Harv Bus Rev; 94.

10. VanLare JM, Conway PH. Value-based purchasing-national programs to move from volume to value. N Engl J Med 2012; 367:292-5.
11. Dietz N, Sharma M, Alhourani A, et al. Bundled payment models in spine surgery: current challenges and opportunities, a systematic review. World Neurosurg 2019;123:177-83.

12. Sullivan R, Jarvis LD, O'Gara T, et al. Bundled payments in total joint arthroplasty and spine surgery. Curr Rev Musculoskelet Med 2017;10:218-23.

13. Kahn EN, Ellimoottil C, Dupree JM, et al. Variation in payments for spine surgery episodes of care: implications for episode-based bundled payment. J Neurosurg Spine 2018;29:214-9.

14. Segal DN, Wilson JM, Staley C, et al. The 5-item modified frailty index is predictive of 30 -day postoperative complications in patients undergoing kyphoplasty vertebral augmentation. World Neurosurg 2018;116:e225-31.

15. Neuman BJ, Ailon T, Scheer JK, et al. Development and validation of a novel adult spinal deformity surgical invasiveness score: analysis of 464 patients. Neurosurgery 2018; 82:847-53.

16. Aebi M, Grob D. SSE Spine Tango: a European Spine Registry promoted by the Spine Society of Europe (SSE). Eur Spine J 2004;13:661-2.

17. Santana A, Afonso P, Maria A, et al. Activity Based Costing and Time-Driven Activity Based Costing: Towards an Integrated Approach. In: ICOPEV - 2nd International Conference on Project Evaluation, Guimarães/PT 2014.

18. De Ryck D, Tambeur W, Vanden Boer G, et al. Analyse des Flux Financiers des hopitaux Généraux belges en Fonction du case-mix. J d'Economie Medicale 2008;26:16-27.

19. Yeramaneni S, Ames CP, Bess S, et al. Center variation in episodeof-care costs for adult spinal deformity surgery: results from a prospective, multicenter database. Spine J 2018;18:1829-36.

20. Benahmed N, Briat G, Rondia K, Vlayen J. [Routine preoperative testing in adults undergoing elective non-cardiothoracic surgery]. Rev Med Brux 2018;39:101-7.

21. Chotai S, Sivaganesan A, Parker SL, et al. Drivers of Variability in 90-day Cost for Primary Single-level Microdiscectomy Eric Stephens, MBA, CAP \#. DOI: 10.1093/neuros/nyy209. 